\title{
National Institute of Child Health and Human Development
}

National Cancer Institute

\section{Source}

National Cancer Institute. National Institute of Child Health and Human Development. NCI Thesaurus. Code C19754.

An institute within the National Institutes of Health that conducts and supports research on all stages of human development from preconception to adulthood, to better understand the health of children, adults, families, and communities. 